\title{
Family physician and referral system adherence in Iranian primary healthcare system
}

\author{
MOBIN SOKHANVAR ${ }^{1, A, B, E, F}$, MOHAMMAD JAVAD KABIR ${ }^{2, B, E, G}$, HOSSEIN BEVRANI $^{3, A, c, E}$, \\ ORCID ID: 0000-0003-0923-1385 ORCID ID: 0000-0001-7960-7670 \\ SHIRIN NOSRATNEJAD ${ }^{4, A, C-E}$, ALI JANATII, A, D, E, G, EDRIS HASANPOOR 5, D, E \\ ORCID ID: 0000-0001-8472-648X $\quad$ ORCID ID: 0000-0003-4295-0824' $\quad$ ORCID ID: 0000-0002-5155-2679
}

${ }^{1}$ Iranian Center of Excellence in Health Management, School of Management and Medical Informatics, Tabriz University of Medical Sciences, Tabriz, Iran

${ }^{2}$ Health Management and Social Development Research Center, Golestan University of Medical Sciences, Gorgan, Iran

${ }^{3}$ Department of Statistics, Faculty of Mathematical Sciences, University of Tabriz, Tabriz, Iran

${ }^{4}$ Iranian Center of Excellence in Health Management, School of Management and Medical Informatics,

Tabriz University of Medical Sciences, Tabriz, Iran

${ }^{5}$ Department of Healthcare Management, Research Center for Evidence-Based Health Management, Maragheh University of Medical Sciences, Maragheh, Iran

A - Study Design, B - Data Collection, C - Statistical Analysis, D - Data Interpretation, E - Manuscript Preparation, F - Literature Search, G - Funds Collection

Summary Background. One of the main strategies to improve access to and the quality and efficiency of healthcare systems is a family physician program (FPP) as the primary care provider within an appropriate referral system.

Objectives. The aim of this study was to investigate the level of adherence of rural insured patients to family physicians (FP) and the referral system, as well as factors that affect self-referral.

Material and methods. This multicenter, cross-sectional study was conducted between April 2018 and February 2019 in East Azerbaijan Province, Iran. A questionnaire-based survey was used to collect data on patient characteristics, adherence to the FPP and referral system, and the reasons for self-referral from 1,553 participants recruited using multistage cluster sampling.

Results. Overall, $58.9 \%$ of participants adhered to the FPP and referral system. The total self-referral rate was $41.1 \%$, including $24.3 \%$ patients who had attended an FP appointment only to obtain a referral code, and $16.8 \%$ had self-referred directly. Data on age, sex, family monthly expenditure, and place of residence were associated with self-referral. Structural pitfalls, societal knowledge and attitudes, and cultural challenges were identified as the patients' reasons for self-referring. Within these categories, the most frequent reasons included uncertainty about the knowledge and skills of FPs (74.2\%), easy and inexpensive access to specialized services $(66.7 \%)$, better quality of specialized services $(59 \%)$, and a lack of awareness of the FPP and the services provided at level 1.

Conclusions. A significant percentage of enrollees did not adhere to the FPP and referral system. Considering the unwelcome consequences of self-referral, designing and implementing practical interventions seems essential in order to encourage patients to be more compliant.

Key words: physicians, family, referral and consultation, primary health care.

Sokhanvar M, Kabir MJ, Bevrani H, Nosratnejad S, Janati A, Hasanpoor E. Family physician and referral system adherence in Iranian primary healthcare system. Fam Med Prim Care Rev 2020; 22(2): 158-165, doi: https://doi.org/10.5114/fmpcr.2020.95325.

\section{Background}

Over recent decades, no strategy more effective and feasible than primary health care $(\mathrm{PHC})$ has been implemented to achieve "health for all" in the world [1]. Evidence suggests that healthcare systems, with a focus on PHC, have had a positive impact on health outcomes, healthcare quality, access to and continuity of healthcare, system efficiency and financial sustainability, as well as public satisfaction [2-4]. The best approach to providing PHC is suggested to be through the use of FPP [5]. The World Health Organization (WHO) introduced the Family Physician Program (FPP) as a vital tool for improving quality, reducing costs, and ensuring effectiveness and equality [6]. Establishing an FPP within a healthcare system can support an appropriate referral system that works more efficiently and increases access to services [5, 7]. Creating an effective referral system to connect different levels of a healthcare system can increase efficiency [8]. In referral-based healthcare systems, within which
FPs work as the gatekeepers, the cost and use of specialized services decreases as the quality, coordination, and continuity of preventative healthcare is improved $[9,10]$.

\section{Primary health care, FPs, and the referral system in Iran}

The healthcare system of Iran consists of three levels. The first level is related to PHC, while the second and third levels concern hospital services provided in urban areas [11]. PHC in Iran is provided through a healthcare network which was established in the mid-1980s, referred to as the first major reform in Iran's healthcare system [6]. Health houses in rural areas provide PHC through trained local residents called "Behvarz", under the supervision of rural healthcare centers. A rural healthcare center is administered by a physician who works with a healthcare team [12].

In 2005, the second major reform in Iran started: the establishment of an FPP for the rural population and cities with 
a population of fewer than 20,000 . These populations are covered by a rural health insurance program funded by the Iran Health Insurance Organization (IHIO), one of the main insurance organizations in Iran, covering $41 \%$ of the total population, including the rural residents $[12,13]$. This rural FPP reform in Iran was mentioned in the third national development plan (2000-2004) and also mentioned in the fourth and fifth development programs. According to these plans, the Higher Council of Health Insurance ( $\mathrm{HCHI}$ ) was obliged to establish an FPP and referral system in rural areas [14]. In this program, an FP is responsible for providing healthcare services for all of their designated population without any discrimination. Patients are referred to specialists (the second and third levels of the healthcare system) through the established referral system and under the responsibility of the FP $[15,16]$.

\section{FP and referral system adherence: challenges and their causes}

Despite all the benefits that adhering to the FPP and referral system can offer for patients - not to mention the healthcare system - there are some situations when people bypass their designated FP. Self-referral to specialized services results in unnecessary payment by individuals, compromised communication of patient health information, and loss of the benefits of continuity of care. The healthcare system also suffers from self-referral, as the costs of these specialized services increase, service quality is reduced, and mortality and morbidity increase $[17,18]$. Direct referral to a specialist can result from challenges within the referral system. These challenges include a lack of adequate communication between the levels of healthcare service providers [19], inappropriate guidelines [20], a lack of referral completion by healthcare professionals [21-23], and a lack of proper communication tools and equipment, which affects the speed, accuracy, and willingness to complete referrals [24, 25].

In a cross-sectional telephone survey of 606 users of specialists by Braun et al., the self-referral rate was 24.4 percent [26]. The results of a survey by Gross et al. showed that one-third of them prefer self-referring to specialists. Living in the periphery, having a low level of education, being male, and being in fair or poor health were the main predictors for preferring self-referral [27]. However, in a study by Kulu-Glasgow et al., there are some conflicting findings. Based on their results, patients who live in more urban areas and are better educated are more likely to bypass their FPs before visiting a specialist. The need for typical specialist help, the better facilities at the specialist, the desire to save time, and the chance to avoid paying for a consultation with an FP were the reasons given for self-referral [28].

In Iran, despite over a decade of this FPP and referral system operating in rural settings, there are still a number of challenges $[29,30]$. These include the lack of appropriate communication between different levels of the referral system and insufficient knowledge about the referral system, which can increase self-referral, reverse referral, and bypass the referral system [31, 32]. In Kashan, Isfahan province, $29.7 \%$ of the rural population has self-referred to receive specialized services. The reasons given for this were that specialists were more skilled, seeing an FP for a referral was a waste of time, there was little information about the referral system, and there was good communication with clients at the level of specialists [33]. Despite these shortcomings, the implementation of the FPP and referral system in rural settings in Iran has brought about remarkable improvements in the areas of maternal mortality, life expectancy, and controlling infectious diseases [15]. Therefore, an investigation into the status of patients' adherence to the FPP and referral system along with its causes and determinants can provide valuable information for healthcare policy-makers and authorities which can strengthen the system. Furthermore, these results can facilitate informed decision-making in other countries with a similar healthcare context.

\section{Material and methods}

\section{Study design}

This multicenter, cross-sectional study was conducted between April 2018 and February 2019. A questionnaire-based survey was used to collect quantitative and qualitative data for this mixed-method study.

\section{Setting}

Iran has a population of about 79 million (geographically divided into 31 provinces) and is located in southwest Asia (the Middle East). It is placed within the Eastern Mediterranean Region (EMR-B) by the WHO [34]. According to WHO statistics, healthcare spending as a percentage of GDP has increased from $4.6 \%$ in 2000 to $6.9 \%$ in 2014 [35]. Iran has public cooperative healthcare. Public health, medical treatment, and medical education are provided by the Ministry of Health and Medical Education (MOHME) through a hybrid structure [11]. East Azerbaijan, one of the largest Iranian provinces, has a population of $3,909,652$, consists of 22 counties, and is located in the northwest of Iran, bordering Armenia, the Republic of Azerbaijan, Ardabil Province, West Azerbaijan Province, and Zanjan Province. The capital of East Azerbaijan is Tabriz.

\section{Study population and sampling}

The study population consisted of patients who were referred to select Rural Family Physician Centers (RFPC) during the data collection period. A multistage cluster sampling approach was used [36]. The counties within the province were classified into five categories according to population size. From each group of counties, one city was randomly selected (Fig. 1). Accordingly, the counties of Tabriz, Maragheh, Osku, Ajabshir, and Shabestar-comprising $61.4 \%$ of the province's population - were selected. The RFPCs from these counties were subsequently stratified into five clusters based on geographical zones (North, South, East, West, and Central areas). Finally, one RFPC was randomly selected within each of these geographic zones (five RFPCs in each county).

The sample size was estimated using the following formula: $n=\left[z^{2} p(1-p)\right] / e^{2}$, where $n$ is the sample size, $z$ is the confidence level at $95 \%, p$ is the expected prevalence (0.297), and $e$ is the precision (margin of error $=0.54$ ). The expected prevalence was estimated using results from a previous study in the rural areas of Iran, where the probability of self-referral was estimated to be 0.297 [33]. Based on this formula, the minimum sample size needed was 273 patients in each county.

\section{Inclusion and exclusion criteria}

The inclusion criteria were a willingness to participate in the study, the ability to speak in Turkish or Persian, and eligibility for rural insurance. Individuals referred for follow-up (blood pressure control, pregnancy follow-up, vaccines, etc.) and those who did not have an appointment with an FP were excluded.

\section{Data collection}

Data were collected using a questionnaire administered by healthcare personnel working in the RFPC in order to ensure open and constructive communication with patients and to obtain accurate information. These staff members are generally natives and have at least a bachelor's degree in Nursing, Midwifery, or Family Health. All of the staff who were involved in completing the questionnaires received training. A pilot study was carried out with 10 staff members and 20 patients to assess the clarity and interpretability of the questionnaire; the questionnaire was refined using feedback from the pilot study. 


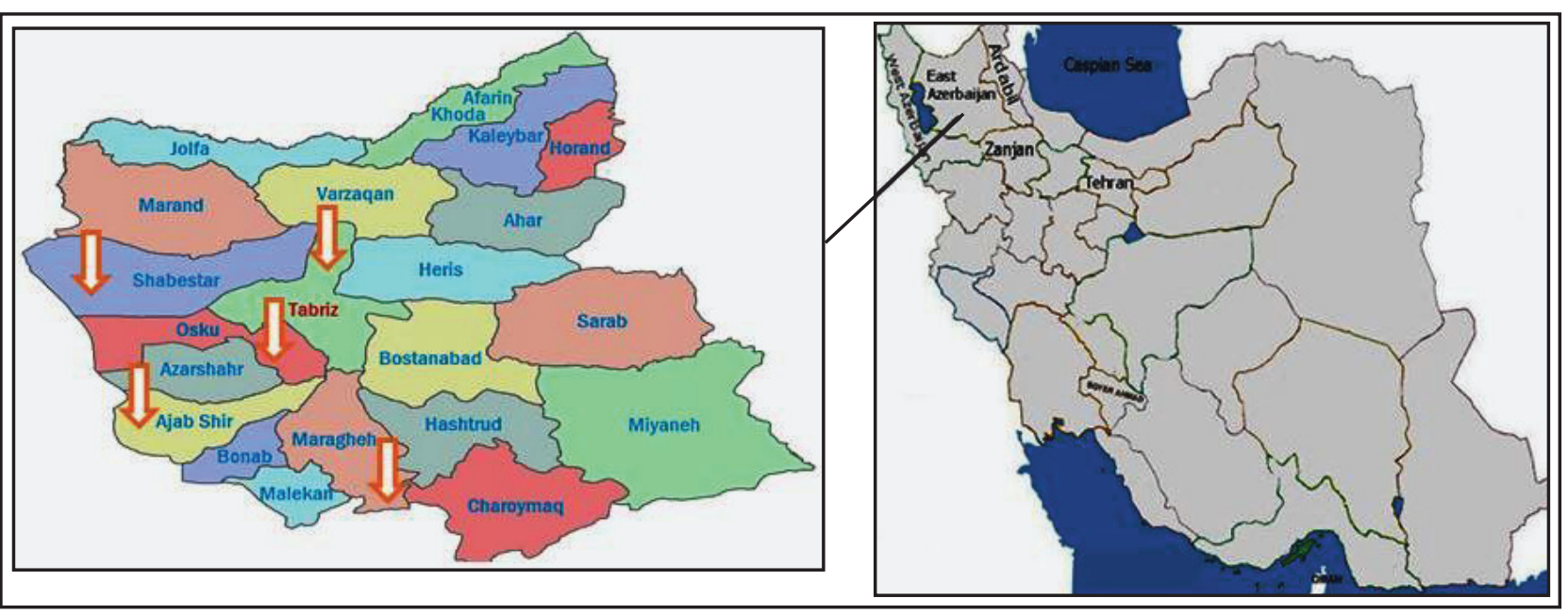

Figure 1. Selected counties of East Azerbaijan province

All surveys were administered in person. For children under the age of 18 years, questionnaires were completed by asking their parents. The questionnaire consisted of mostly closed-ended questions pertaining to participant characteristics and current health status. Additionally, participants were asked the purpose of their appointment with an FP (i.e., visit and consultation, getting a referral code without consultation, reverse referral) in order to determine adherence - patients whose purpose for the appointment was to get a referral code without a consultation or a reverse referral were considered to have skipped the FPP and referral system. These patients were asked one additional open-ended question regarding their reasons for skipping the FPP and referral system.

\section{Data analysis}

SPSS 23.0 (SPSS, Inc., Chicago, IL, USA) was used to analyze the data. Chi-squared tests were used to test for the association between patients' categorical characteristics and adherence to the FPP and referral system. The significance level was set at $p<$ 0.05 . Following this univariate analysis, variables with a $p$-value of $<0.25$ were taken forward into a logistic regression analysis. Content analysis was used to analyze the participants' responses to the open-ended question. NVivo (QSR International Pty Ltd., version 11.4.1) was used to manage this qualitative data. Verbatim survey responses were coded by MS, AJ, and SHN independently using inductive reasoning; these codes were driven in accordance with phrasing used by the participants [37]. After all the responses were coded, the coding team discussed 13 discrepancies in order to resolve them. In cases where a con- sensus was not achieved ( $n=6), \mathrm{MjK}$ and EH's opinions also were considered. The extracted codes were then classified into related sub-categories. The mean $(95 \% \mathrm{Cl})$ of the category-specific kappa values was $0.83(0.78-0.88)$.

\section{Ethics approval and consent to participate}

Ethical approval was obtained from the Ethical Committee of Research Vice Chancellor of Tabriz University of Medical Sciences (IR.TBZMED.REC.1396.835). Informed consent was obtained from all patients prior to their inclusion in the study. In addition, for all patients under 18 years old, informed consent was obtained from their parents.

\section{Results}

The study sample was composed of 1,553 patients referred to the 25 RFPCs from Tabriz (385, 24.8\%), Maragheh (313, 20.1\%), Osku (284, 18.3\%), Ajabshir (292, 18.8\%), and Shabestar (279, $18.0 \%)$. The mean age of the patients was 37.2 years $(S D=18.9)$, and $66.1 \%$ were female (Table 1 ). Most patients (32.1\%) had four family members. Only $7.6 \%$ of patients were widowed or divorced, and $21.8 \%$ were single. The educational level of more than half of the participants were elementary school and diploma degree. $35.7 \%$ of the patients had a monthly family expenditure of between 500,000 and 1,000,000 Iranian Tomans. More than two thirds of the patients stated they were in good or very good health. The most common (58.9\%) reason for having an appointment with an FP was to visit or consult. The total non-adherence rate was $41.1 \%$.

\begin{tabular}{|c|c|c|c|c|c|}
\hline Characteristics & $n$ & $\%$ & Characteristics & $n$ & $\%$ \\
\hline \multicolumn{3}{|c|}{ Patient characteristics $(n=1,553)$} & \multicolumn{3}{|c|}{ Patient's/parent's education $(n=1,450)$} \\
\hline \multicolumn{3}{|l|}{ Age (years) } & Illiterate & 213 & 14.7 \\
\hline $1-18$ & 248 & 16.0 & Elementary school & 372 & 25.6 \\
\hline $19-25$ & 204 & 13.1 & Middle school & 217 & 15.0 \\
\hline $26-35$ & 342 & 22.0 & High school & 141 & 9.7 \\
\hline $36-45$ & 280 & 18.0 & Diploma degree & 364 & 25.1 \\
\hline $46-55$ & 203 & 13.1 & Academic degree & 143 & 9.9 \\
\hline $56-65$ & 141 & 9.1 & \multicolumn{3}{|c|}{ Monthly family expenditure (Iranian Tomans) } \\
\hline $65<$ & 135 & 8.7 & $<500,000$ & 189 & 12.2 \\
\hline \multicolumn{3}{|l|}{ Sex } & $500,000-1,000,000$ & 555 & 35.7 \\
\hline Male & 527 & 33.9 & $1,000,000-1,500,000$ & 520 & 33.5 \\
\hline Female & 1026 & 66.1 & $1,500,000-2,000,0000$ & 190 & 12.2 \\
\hline
\end{tabular}




\begin{tabular}{|c|c|c|c|c|c|}
\hline Characteristics & $n$ & $\%$ & Characteristics & $n$ & $\%$ \\
\hline \multicolumn{3}{|c|}{ Number of family members } & $>2,000,000$ & 99 & 6.4 \\
\hline$\leq 2$ & 248 & 15.9 & \multicolumn{3}{|c|}{ Stated health status ( $n=1,553)$} \\
\hline 3 & 352 & 22.7 & Bad or very bad & 92 & 5.9 \\
\hline 4 & 498 & 32.1 & Moderate & 354 & 22.8 \\
\hline 5 & 261 & 16.8 & Partially good or good & 766 & 49.3 \\
\hline$\geq 6$ & 194 & 12.5 & Very good & 341 & 22.0 \\
\hline \multicolumn{3}{|l|}{ Marital status } & \multicolumn{3}{|c|}{ The purpose for the appointment $(n=1,553)$} \\
\hline Single & 338 & 21.8 & Visit or consultation & 914 & 58.9 \\
\hline Married & 1097 & 70.6 & Getting referral code & 378 & 24.3 \\
\hline Widowed/divorced & 118 & 7.6 & Having reverse referral & 261 & 16.8 \\
\hline
\end{tabular}

\begin{tabular}{|c|c|c|}
\hline Patient characteristics & $x^{2}$ & $p$ \\
\hline Age & 7.743 & 0.243 \\
\hline Sex & 5.310 & 0.012 \\
\hline Number of family members & 7.410 & 0.192 \\
\hline Marital status & 1.281 & 0.527 \\
\hline Patient's/parent's education & 4.713 & 0.452 \\
\hline Monthly family expenditure (Iranian Tomans) & 7.717 & 0.103 \\
\hline County & 49.206 & $<0.001$ \\
\hline
\end{tabular}

\begin{tabular}{|c|c|c|c|c|c|c|}
\hline Patient characteristics & B & S.E. & Wald & Exp. (B) & $95 \% \mathrm{Cl}$ & $p$ \\
\hline \multicolumn{7}{|l|}{ Age } \\
\hline $1-18$ & 0.307 & 0.245 & 1.579 & 1.360 & $0.842-2.197$ & 0.029 \\
\hline $19-25$ & 0.405 & 0.245 & 2.736 & 1.499 & $0.928-2.422$ & 0.098 \\
\hline $26-35$ & 0.245 & 0.236 & 1.074 & 1.277 & $0.804-2.030$ & 0.300 \\
\hline $36-45$ & 0.307 & 0.244 & 1.576 & 1.359 & $0.842-2.193$ & 0.209 \\
\hline $46-55$ & 0.545 & 0.244 & 4.998 & 1.725 & $1.070-2.783$ & 0.025 \\
\hline $56-65$ & 0.186 & 0.259 & 0.515 & 1.205 & $0.725-2.002$ & 0.473 \\
\hline \multicolumn{7}{|l|}{ Sex } \\
\hline Male & 0.233 & 0.114 & 4.204 & 1.263 & $1.010-1.578$ & 0.040 \\
\hline \multicolumn{7}{|c|}{ Number of family members } \\
\hline$\leq 2$ & -0.125 & 0.217 & 0.333 & 0.882 & $0.576-1.351$ & 0.564 \\
\hline 3 & -0.091 & 0.208 & 0.192 & 0.913 & $0.607-1.372$ & 0.661 \\
\hline 4 & -0.130 & 0.200 & 0.423 & 0.878 & $0.593-1.300$ & 0.516 \\
\hline 5 & -0.271 & 0.207 & 1.717 & 0.763 & $0.509-1.144$ & 0.190 \\
\hline \multicolumn{7}{|c|}{ Monthly family expenditure } \\
\hline$<500,000$ & -0.260 & 0.258 & 1.013 & 0.771 & $0.465-1.279$ & 0.314 \\
\hline $500,000-1,000,000$ & -0.437 & 0.227 & 3.710 & 0.646 & $0.414-1.008$ & 0.050 \\
\hline $1,000,000-1,500,000$ & -0.291 & 0.231 & 1.577 & 0.748 & $0.475-1.177$ & 0.209 \\
\hline $1,500,000-2,000,0000$ & -0.542 & 0.262 & 4.303 & 0.581 & $0.348-0.971$ & 0.038 \\
\hline \multicolumn{7}{|l|}{ County } \\
\hline Maragheh & -0.860 & 0.176 & 23.889 & 0.423 & $0.300-0.598$ & $<0.001$ \\
\hline Osku & -0.107 & 0.180 & 0.352 & 0.899 & $0.632-1.279$ & 0.553 \\
\hline Ajabshir & -0.427 & 0.172 & 6.149 & 0.652 & $0.466-0.914$ & 0.013 \\
\hline Shabestar & -0.799 & 0.186 & 18.462 & 0.450 & $0.313-0.648$ & $<0.001$ \\
\hline
\end{tabular}

Univariate analysis showed significant associations between sex and county with patients' adherence/non-adherence choices (Table 2).

Age, sex, number of family members, monthly family expenditure, and county were carried into the logistic regression model (Table 3). The logistic regression analysis showed that patients between $1-18$ years old and between $45-55$ years old were more likely to be self-referred $(\mathrm{OR}=1.360 ; 95 \% \mathrm{Cl}[0.842-$ 2.197]; $p=0.029$ and $\mathrm{OR}=1.725 ; 95 \% \mathrm{Cl}$ [1.070-2.783]; $p=$ 0.025 , respectively). Male patients were 1.26 times more likely to be self-referred than female patients $(O R=1.263 ; 95 \% \mathrm{Cl}$ [1.010-1.578]; $p=0.040$ ). Patients with monthly household ex- 


\begin{tabular}{|c|c|}
\hline Categories & Sub-categories \\
\hline Structural pitfalls & $\begin{array}{l}\text { - Lack of access to the FPP during evenings and at night } \\
\text { - Registering individuals at family physician centers (FPC) based on geographical areas } \\
\text { rather than individual preferences } \\
\text { - } \text { Failure to complete the Electronic Health Record } \\
\text { - } \text { Eo electronic communication established between levels of the referral system } \\
\text { - A slight difference in the cost of services outside the referral system } \\
\text { - Shortage of manpower, crowded FPCs, and excessive delays }\end{array}$ \\
\hline $\begin{array}{l}\text { Societal knowledge and } \\
\text { attitudes }\end{array}$ & $\begin{array}{l}\text { - Uncertainty about knowledge and skills of the FP and the staff working in the FPC } \\
\text { - Lack of awareness of the FPP and the services provided at level } 1 \text { (PHC) } \\
\text { - PHC is not effective } \\
\text { - Urgent need for a specialist and advanced facilities to solve a health problem } \\
\text { - Better quality of second- and third-level services (specialized services) }\end{array}$ \\
\hline Cultural challenges & $\begin{array}{l}\text { - Direct referral to specialist and sub-specialist is a status symbol of high social class } \\
\text { - Low cost is equivalent to poor quality } \\
\text { - Consumerism }\end{array}$ \\
\hline
\end{tabular}

penses between 500,000 and 1,000,000 Iranian Tomans and between 1,500,000 and 2,000,000 Iranian Tomans were 0.36 and 0.42 times less likely to be self-referred, respectively, than those who had monthly household expenses over 2,000,000 Iranian Tomans ( $\mathrm{OR}=0.646 ; 95 \% \mathrm{Cl}[0.414-1.008] ; p=0.050$ and $\mathrm{OR}=$ $0.581 ; 95 \% \mathrm{Cl}[0.348-0.971] ; p=0.038$, respectively). Patients from Maragheh $(\mathrm{OR}=0.423 ; 95 \% \mathrm{Cl}[0.300-0.598] ; p<0.001)$, Ajabshir $(\mathrm{OR}=0.652 ; 95 \% \mathrm{Cl}[0.466-0.914] ; p=0.013)$, and Shabestar (OR $=0.450 ; 95 \% \mathrm{Cl}[0.313-0.648] ; p<0.001)$ were 0.42 , 0.65 , and 0.45 times less likely to be self-referred.

A total of 639 people who skipped the FPP and referral system were asked to answer an open-ended question. Eighty-one percent of the participants (520/639) responded. The most frequently cited reasons included uncertainty about the FP's knowledge and skills (386/520, 74.2\%), easy and inexpensive access to specialized services $(347 / 520,66.7 \%)$, better quality of specialized services $(307 / 520,59.0 \%)$, and a lack of awareness of the FPP and the services provided at level 1 (PHC). Performing content analysis steps led to the extraction of three categories for "drivers for skipping FPP and referral system": "structural pitfalls," "society's knowledge and attitude," and "cultural challenges." Each of these three categories is explained with sub-categories, which are presented in Table 4.

\section{Discussion}

Since 2005, the Iranian healthcare system has operated an FPP and referral system in rural communities in the context of the existing healthcare network. The program was designed and implemented to ensure that all people receive services under the supervision of an FP and within the defined pathways. However, pitfalls in the existing system have resulted in patient self-referral to specialized services. This is something that has never been properly investigated.

In this study, the level of adherence to the FPP and referral system of 1,553 rural insured patients was investigated in five counties of East Azerbaijan Province, Iran. The results showed that 16.8 percent of the patients received specialized services without contacting their FP, which were introduced in this study as patients "having reverse referral." This is less than the $29.7 \%$ of a rural population reported by Rasoulynejad, who investigated the self-referral rate to level 2 and level 3 services (specialists) [33]. On the one hand, the time at which these studies were conducted could explain the dissimilarity of the results. Rasoulynejad's study was conducted just one year after the implementation of the FPP. The passage of time may have improved the program's coverage, expanded the infrastructure required, and strengthened its effects $[38,39]$. On the other hand, in the current study $24.3 \%$ of patients visited their FP not for a clinical consultation, but only to get a referral code to receive specialized services, which are categorized within the selfreferral group. Therefore, our study found more self-referral than Rasoulynejad's study. The levels of the healthcare system which were studied may also be a reason for the differences in the results.

The rate of self-referral in this study $-41.1 \%$ - is far more than the rate reported in studies 7 conducted in the United States, where $9.7 \%$ and $14.9 \%$ of lung cancer and colorectal cancer patients, respectively, self-refer [40]. Our self-referral rate was also higher than that reported by Braun et al. 24.42 percent, bypass gatekeepers which means self-referral to receive services [26]. FPP and referral system non-adherence may have adverse consequences, such as reducing the quality of care, patients receiving unnecessary specialized services, increasing the costs to the patients, and hindering the healthcare system's effective and efficient functioning $[6-8,10,41]$. Therefore, the study of influential factors that drive self-referral is of great importance.

In this study, the role of patient characteristics in the adherence and non-adherence of patients to the referral system was investigated through logistic regression. Patients between 1 and 18 years old and between 45 and 55 years old were more likely to self-refer. This result is in contrast with the results of previous studies (Kulu-Glasgow et al. in the Netherlands [28] and Forrest et al. in the United States [42]), which found no association between age and self-referral to specialists. Nor has similar evidence been reported in other studies conducted in Iran. Within the age group of 1-18 years, self-referral to a specialist may be more frequent due to parents' worries about their children's health and their concerns about the ability of their FP in the field of pediatrics. Janicke et al. confirmed the role of mothers' perceptions of child health in children's healthcare use [43].

Our results also revealed that men were 1.26 times more likely to self-refer than women. This result is in line with the findings of Gross et al. [27], though no such results were obtained in a study conducted in the Netherlands [28] or in two studies from the United States [40,42]. Among the rural population in Iran, women have more interaction with RFPCs because they receive a variety of services, including family planning, prenatal care, and child care [44]. These interactions may lead to greater trust and, consequently, a desire to adhere to the FPP.

Furthermore, monthly household expenditure and place of residence (selected counties) were associated with the patient's choice (adherence/non-adherence). According to Pollack et al., patients with higher income are more likely to self-refer to specialists [40]. Although the current study did not examine the longitudinal effect of increased monthly expenditure (as an alternative indicator for monthly income) on the patient's tendency to self-refer, the role of financial means cannot be ignored. In regard to the place of residence, the results revealed that patients from Maragheh, Ajabshir, and Shabestar were less 
likely to self-refer. These counties are further from Tabriz (the capital of province) than Osku and the rural areas of Tabriz. It is possible that, due to the high concentration of specialists and advanced medical centers, it is easier for patients living close to Tabriz to refer themselves directly. The presence of specialized and sub-specialized clinics in teaching hospitals (level 3 of the healthcare system) in Tabriz, which have low fees for services (even for self-referrals), can also be an effective incentive. In line with these results, Kulu-Glasgow et al. concluded that self-referral to specialists was more common among those living in highly urbanized settings [28].

International evidence [19-25], as well as the results of studies conducted in Iran [29-32], has identified technical and structural pitfalls of referral systems as a major reason for patient self-referral. Data regarding patients' reasons for skipping the FPP and referral system are categorized into three sub-themes: structural pitfalls, societal knowledge and attitudes, and cultural challenges. Uncertainty about FPs' knowledge and skills, easy and inexpensive access to specialized services, better quality of specialized services, and a lack of awareness of the FPP and the services provided at level 1 were the most frequent reasons for skipping the FPP and referral system. A lack of electronic communication between the levels of the referral system was one structural challenge that was identified; this has been mentioned previously in the United States (Valders et al., 2009) and Iran (Eskandari et al., 2013; Afkar et al., 2013) as a main reason for patient self-referral. Manpower shortages, crowded FPCs, and long delays - categorized in the current study as other structural challenges - have been identified as main reasons for patients self-referring in Iran and the United States [26, 28, 33]. Under-staffing estimates for FPs, nurses, and nutritional experts in health teams working in Iranian RFPCs range from $34 \%$ to $60 \%[45]$.

Results from the sub-category "societal knowledge and attitudes" (uncertainty about the knowledge and skills of the FPs, the better quality of specialized services, and a lack of awareness of the FPP and the services provided at level 1) are in line with the results of Rasoulynejad [33]. Cultural challenges that represent common assumptions of Iranian society are the last sub-category. These assumptions can influence people's behavior, and therefore cultural development plans should address these challenges.

This study provides substantial evidence of patient adherence to the FPP and referral system in East Azerbaijan Province, but it is not without limitations. First, although the FPP and re- ferral system are being implemented throughout the country in an integrated manner, the demographic characteristics of patients and the social, cultural, and economic conditions in Iranian provinces vary. This should be considered when generalizing the results of this study to other provinces. The second limitation is that participants have been sampled from the RFPC (first level of the referral system). These people are covered by the IHIO, which covers 41 percent of the total population. Therefore, if the research participants were chosen at the level of specialist services (levels 2 and 3), different results may be obtained due to the different population composition.

\section{Conclusions}

The Iranian healthcare system established the FPP and referral system in order to provide Universal Health Coverage (UHC) effectively and efficiently. When patients skip this FPP and referral system, it can lead to increased costs, reduced quality, and inefficiencies and inequalities in access to health services, which is in conflict with the main goals of the healthcare system. This study showed that a significant percentage of people did not adhere to the FPP and referral system due to structural and cultural challenges and to societal knowledge and attitudes towards the system. Considering the unwelcome consequences of self-referral, designing and implementing interventions to improve the situation is essential. In this regard, interventions in the healthcare system, medical education system, and payment system - alongside culture-building and public education - are required in Iran, as concluded by Naseriasl et al. Accordingly, establishing a health information system between the different levels of the healthcare system, developing referral guidelines, establishing specialty courses for FPs, and applying mixed payment systems are the most important interventions [46]. Also, considering that both patients and FPs need accurate and quick access to healthcare information in order to make appropriate decisions, establishing an electronic health record is recommended. Electronic health records and e-referral technology can facilitate the referral process for patients and all other people involved $[25,47]$.

Acknowledgements. This article is a part of PhD thesis supported by Tabriz University of Medical Sciences [Thesis no. $314 / D / M]$. We would like to thank P. Compston for her help with the language editing of this paper.

Source of funding: This study was funded (Approval code: 59025) by Tabriz University of Medical Sciences, Tabriz, Iran. Conflicts of interest: The authors declare no conflicts of interest.

\section{Refrences}

1. World Health Organization. World Health Report calls for return to primary health care approach. 2008 [cited 30.04.2010]. Available from URL: http://www. hst. org. za/news/20041888.

2. De Maeseneer J, Weel $C$ van, Egilman D, et al. Strengthening primary care: addressing the disparity between vertical and horizontal investment. Br J Gen Pract 2008; 58(546): 3-4.

3. Atun RA, Menabde N, Saluvere K, et al. Introducing a complex health innovation - primary health care reforms in Estonia (multimethods evaluation). Health Policy 2006; 79(1): 79-91.

4. Damme W van, Lerberghe W. van, Boelaert M. Primary health care vs. emergency medical assistance: a conceptual framework. Health Policy Plan 2002; 17(1): 49-60.

5. Villanueva T. Family Medicine, the specialty of the future: the Portuguese situation within the European context. Int Arch Med 2009; 11(1): 36, doi: 10.1186/1755-7682-2-36.

6. Gorji AH, Royani S, Mohseni M, et al. Primary health care quality in Iran: a systematic review and meta-analysis. Fam Med Prim Care Rev 2019; 21(1): 71-77.

7. Weel $C$ van, Rosser WW. Improving health care globally: a critical review of the necessity of family medicine research and recommendations to build research capacity. Ann Fam Med 2004; 2(Suppl. 2): S5-S16.

8. Xu J, Wang W, Li Y, et al. Analysis of factors influencing the outpatient workload at Chinese health centres. BMC Health Serv Res 2010; 10(1): 151, doi: 10.1186/1472-6963-10-151.

9. Starfield B, Shi L, Macinko J. Contribution of primary care to health systems and health. Milbank Q 2005; 83(3): 457-502.

10. Casanova C. Starfield B. Hospitalizations of children and access to primary care: a cross-national omparison. Int J Health Serv 1995; 25(2): 283-294. 
11. Mehrdad R. Health system in Iran. JMAJ 2009; 52(1): 69-73.

12. Takian A, Doshmangir L, Rashidian A. Implementing family physician programme in rural Iran: exploring the role of an existing primary health care network. Fam Pract 2013; 30(5): 551-559.

13. Esmaeili R, Hadian M, Rashidian A, et al. Family medicine in Iran: facing the health system challenges. Glob J Health Sci 2014; 7(3): 260-266.

14. Ministry of Health \& Medical Education (MoHME). Family physician instruction. Version 9. Tehran, Iran. 2009: 4-102.

15. Majdzadeh R. Family physician implementation and preventive medicine; opportunities and challenges. Int J Prev Med 2012; 3(10): 665-669.

16. Shariati M, Moghimi D, Rahbar M, et al. Family Physician in health system map in 2025 of Islamic Republic of Iran. National Institute for Health Research of Islamic Republic of Iran. Available from URL: http://ihm.behdasht.gov.ir/Images/UserFiles/26/file/family\%20 doctor.pdf (in Persian).

17. World Health Organization. The hospital in rural and urban districts: report of a WHO Study Group on the Functions of Hospitals at the First Referral Level [meeting held in Geneva, 30 October-5 November 1990]. Geneva: WHO; 1992.

18. Rohrer JE. Planning for community-oriented health systems. New York: American Public Health Association; 1999: 21-37.

19. Valderas JM, Starfield B, Forrest CB, et al. Ambulatory care provided by office-based specialists in the United States. Ann Fam Med 2009; 7(2): 104-111.

20. Forrest CB. A typology of specialists' clinical roles. Arch Intern Med 2009; 169(11): 1062-1068.

21. Gandhi TK, Sittig DF, Franklin M, et al. Communication breakdown in the outpatient referral process. J Gen Intern Med 2000; 15(9): 626-631.

22. Singh $H$, Esquivel A, Sittig DF, et al. Follow-up actions on electronic referral communication in a multispecialty outpatient setting. $J$ Gen Intern Med 2011; 26(1): 64-69.

23. Tian L. Improving knowledge management between primary and secondary healthcare: an e-referral project. Health Care Inform Rev Online 2011; 15: 31-37.

24. Kim $\mathrm{Y}$, Chen $\mathrm{AH}$, Keith $\mathrm{E}$, et al. Not perfect, but better: primary care providers' experiences with electronic referrals in a safety net health system. J Gen Intern Med 2009; 24(5): 614-619.

25. Shaw $L J$, Berker DA de. Strengths and weaknesses of electronic referral: comparison of data content and clinical value of electronic and paper referrals in dermatology. Br J Gen Pract 2007; 57(536): 223-224.

26. Braun BL, Fowles JB, Forrest CB, et al. Which enrollees bypass their gatekeepers in a point-of-service plan? Med Care 2003; 41(7): 836-841.

27. Gross R, Tabenkin H, Brammli-Greenberg S. Who needs a gatekeeper? Patients' views of the role of the primary care physician. Fam Pract 2000; 17(3): 222-229.

28. Kulu-Glasgow I, Delnoij D, Bakker D de. Self-referral in a gatekeeping system: patients' reasons for skipping the general-practitioner. Health Policy 1998; 45(3): 221-238.

29. Nasrollahpour Shirvani S. The implementation of family physician program in Iran: achievements and challenges. J Babol Univ Med Sci 2014; 16(Suppl. 1): 15-26.

30. Honarvar B, Lankarani KB, Ghahramaniet S, et al. Satisfaction and dissatisfaction toward urban family physician program: a population based study in Shiraz, Southern Iran. Int J Prev Med 2016; 7(1), doi: 10.4103/2008-7802.173793.

31. Eskandari M, Abbaszadeh A, Borhani F. Barriers of referral system to health care provision in rural societies in Iran. J Caring Sci 2013; 2(3): 229-236.

32. Afkar A, Pourrza A, Mehrabian F. Family physician performance from the perspective of Gilani customers. Journal of Hospital 2013; 12(1): 39-48.

33. Rasoulynejad S. Patient views for self-referral to specialists. Iran J Public Health 2007; 36(1): 62-67.

34. Dastgerdi MV. Islamic Republic of Iran's Health System: achievements and prospective. Iran J Public Health 2013; 42(Suppl. 1): i-ii.

35. World-Bank-2016. Data: Iran, Islamic Rep [Online] [cited 6.05.2016]. Available from URL: http://data.worldbank.org/indicator/SH.XPD. TOTL.ZS/countries/IR?display=graph.

36. Bennett $S$, Woods T, Liyanage WM, et al. A simplified general method for cluster-sample surveys of health in developing countries. World Health Stat Q 1991; 44(3): 98-106.

37. Elo S, Kyngäs H. The qualitative content analysis process. J Adv Nurs 2008; 62(1): 107-115.

38. Khayyati F, Esmaeil Motlagh M, Kabir MJ, et al. The role of family physician in case finding, referral, and insurance coverage in the rural areas. Iran J Public Health 2011; 40(3): 136-139.

39. Beyrami HJ, Doshmangir L, Ahmadi A, et al, Impact of rural Family Physician programme on maternal and child health indicators in Iran: an interrupted time series analysis. BMJ Open 2019; 9(1): e021761.

40. Pollack CE, Rastegar A, Keating NL, et al. Is self-referral associated with higher quality care? Health Serv Res 2015; 50(5): 1472-1490.

41. Amado CA, Santos SP. Challenges for performance assessment and improvement in primary health care: the case of the Portuguese health centres. Health Policy 2009; 91(1): 43-56.

42. Forrest CB, Weiner JP, Fowles J, et al. Self-referral in point-of-service health plans. JAMA 2001; 285(17): 2223-2231.

43. Janicke DM, Finney JW, Riley AW. Children's health care use a prospective investigation of factors related to care-seeking. Med Care 2001; 39(9): 990-1001.

44. Jahanmehr N, Rashidian A, Khosravi A, et al. A conceptual framework for evaluation of public health and primary care system performance in Iran. Glob J Health Sci 2015; 7(4): 341-357.

45. Kalhor R, Azmal M, Kiaei MZ, et al. Situational analysis of human resources in family physician program: survey from Iran. Mater Sociomed 2014; 26(3): 195-197.

46. NaseriasI M, Janati A, Amini A, et al. Referral system in rural Iran: improvement proposals. Cadernos de Saude Publica 2018; 34 : e00198516.

47. Warren J, White S, Day KJ, et al. Introduction of electronic referral from community associated with more timely review by secondary services. Appl Clin Inform 2011; 2(4): 546-564.

Tables: 4

Figures: 1

References: 47 
Address for correspondence:

Ali Janati, PhD, Assoc. Prof.

Iranian Center of Excellence in Health Management

School of Management and Medical Informatics

Tabriz University of Medical Sciences

Tabriz

Iran

Tel.: +98 9144195377

E-mail: janati1382@gmail.com 